\title{
Coracoclavicular joint: clinical significance and correlation to gender, side and age
}

\author{
Trifon Totlis ${ }^{1}$, Georgios Paparoidamis ${ }^{1}$, Konstantinos Trentzidis ${ }^{1}$, Nikolaos Otountzidis ${ }^{1}$, Maria Piagkou $^{2}$, \\ Konstantinos Natsis ${ }^{1}$ \\ ${ }^{1}$ Department of Anatomy and Surgical Anatomy, School of Medicine, Faculty of Health Sciences, Aristotle University of Thessaloniki, Thessaloniki, Greece \\ ${ }^{2}$ Department of Anatomy, School of Medicine, Faculty of Health Sciences, National and Kapodistrian University of Athens, Athens, Greece
}

\begin{abstract}
Objectives: The aim of this study was to evaluate the incidence of coracoclavicular joint in the Greek population, review the clinical significance for the orthopaedic surgeon and investigate differences between genders, sides and age that may contribute to a better understanding of the accessory joint development.

Methods: The study was performed on the scapulae and claviculae of 140 dried skeletons taken from a local ossuary. After exclusion of damaged bones, the sample of the study consisted of 216 pairs of scapulae and claviculae. Each pair of bones was inspected for the existence of a definite articular facet on the conoid tubercle of the clavicle and also on the superomedial surface of the coracoid process of the scapula. A coracoclavicular joint was considered to be present only when both of these structures existed. Pearson's chi-square test was used to investigate differences between the genders, sides and age of the specimens.

Results: Coracoclavicular joint articular facets were found in 14 out of the 216 bone pairs examined (6.5\%). A statistical significant difference was found only between the age groups. The coracoclavicular joint surfaces were significantly more frequently found in the elderly age group ( $p=0.002$ ). No bones from the youngest age group (45-60 years old) demonstrated a coracoclavicular joint surface, whereas three bones from the median age group (61-75 years old) and 11 from the oldest age group (76+ years old) presented accessory joint surfaces.

Conclusion: The findings of the present study favor those who claim that the coracoclavicular joint could be the result of degenerative changes. From a clinical point of view, this accessory joint may be incidentally noticed in a plain radiograph in asymptomatic patients, but has also been associated with various clinical manifestations of the shoulder region.
\end{abstract}

Keywords: anatomical variation; clavicle; osteology; scapula; shoulder pain; shoulder radiology

Anatomy 2018;12(2):57-60 @2018 Turkish Society of Anatomy and Clinical Anatomy (TSACA)

\section{Introduction}

The coracoclavicular syndesmosis consists of two separate ligaments, the trapezoid and the conoid ligaments. Close to the posterior border of the clavicle, at the junction of the lateral fourth with the rest of the bone, there is a prominent conoid tubercle which gives origin to the conoid part of the coracoclavicular ligament. The trapezoid ligament originates from the oblique or trapezoid ridge which starts from the conoid tubercle and runs anteriorly and laterally. Both ligaments insert on the coracoid process, with the trapezoid ligament being anteriorly and the conoid posteriorly. ${ }^{[1]}$
The conoid tubercle of the clavicle may be enlogated, having a wide ending which is usually an articular surface that articulates with a corresponding articular surface on the footprint of the conoid ligament on the coracoid process. The synovial joint that may be found between those two surfaces is an accessory joint, named the coracoclavicular joint. ${ }^{[2,3]}$ Several articles have been published on the frequency of the coracoclavicular joint and the geographical distribution of this anatomical variation is interesting. ${ }^{[2-6]}$ However, the literature is scarce in studies which analyze the potential effect of the characteristics of the 
sample on the coracoclavicular joint presence. Moreover, there is an ongoing debate in the literature about whether it is hereditary, ${ }^{[4]}$ or an acquired characteristic. ${ }^{[5]}$

It is well-known that shoulder pain is multifactorial. Several pathologies, such as inflammation, degenerative changes, trauma and entrapment neuropathies which are located in different regions around the shoulder might be presented with shoulder pain as the main complaint. Although the presence of the coracoclavicular joint is usually asymptomatic, it has been associated with shoulder pain due to degenerative changes and alterations in shoulder biomechanics. Thus, orthopaedic surgeons should bear in mind this accessory joint since its incidence is not rare and also it can be identified in an anteroposterior shoulder radiograph.

The purpose of the present study was to evaluate the incidence of coracoclavicular joint in the Greek population, review its clinical significance for the orthopaedic surgeons and also to examine for differences between genders, sides and age that may contribute to a better understanding of the accessory joint development.

\section{Materials and Methods}

The study was performed in the scapulae and claviculae of 140 dried skeletons (280 pairs of scapulae and claviculae) taken from a local ossuary. After exclusion of bones with evidence of fracture, postmortem damage, or arthritis, the sample of the study consisted of 216 pairs of scapulae and claviculae (110 right and 106 left), which belonged to 127 individuals ( 66 females and 61 males). When a scapula or a clavicle was damaged, then both bones of that side were excluded. The donors' mean age was $68.5 \pm 10.72$ years (range: $46-96$ years).

Regarding the age of death, the study sample was divided into three age groups. The first group consisted of 55 pairs of specimens aged 46-60 years, the second group consisted of 82 pairs of specimens aged $61-75$ years and the third one consisted of 79 pairs of subjects aged over 75 years.

The presence of the coracoclavicular joint was documented by inspecting the occurrence of a definite articular facet on the conoid tubercle of the clavicle and also on the superomedial surface of the coracoid process of the scapula. Those criteria were based on previous osteological studies. ${ }^{[5,7]}$

Pearson's chi-square test was used to investigate differences between the two genders, sides and age of the specimens. A p-value of $<0.05$ was considered statistically significant. All analyses were conducted using SPSS 19.0 software (SPSS Inc, Chicago, IL, USA).

\section{Results}

The coracoclavicular articular facets were bilaterally present in four and unilaterally in six individuals (Figure 1). Thus, a coracoclavicular joint was considered to be present in 14 out of the 216 bone pairs examined (6.5\%). Seven coracoclavicular joint surfaces were present on the right and seven on the left side ( $\mathrm{p}=0.943)$, while the male to female ratio was $8: 6(\mathrm{p}=0.509)$.

As for the age groups, the coracoclavicular joint surfaces were found significantly more frequent in the elderly age group ( $\mathrm{p}=0.002)$. Namely, no bones from the youngest age group (45-60 years old) demonstrated a coracoclavicular joint surface, whereas three bones from the median age group (61-75 years old) and 11 from the oldest age group (76+ years old) presented those accessory joint surfaces. These findings are summarized in Table $\mathbf{1}$.

\section{Discussion}

The first description of coracoclavicular joint was made by Gruber, in $1861 .{ }^{[8]}$ According to Mann and Hunt ${ }^{[0]}$,
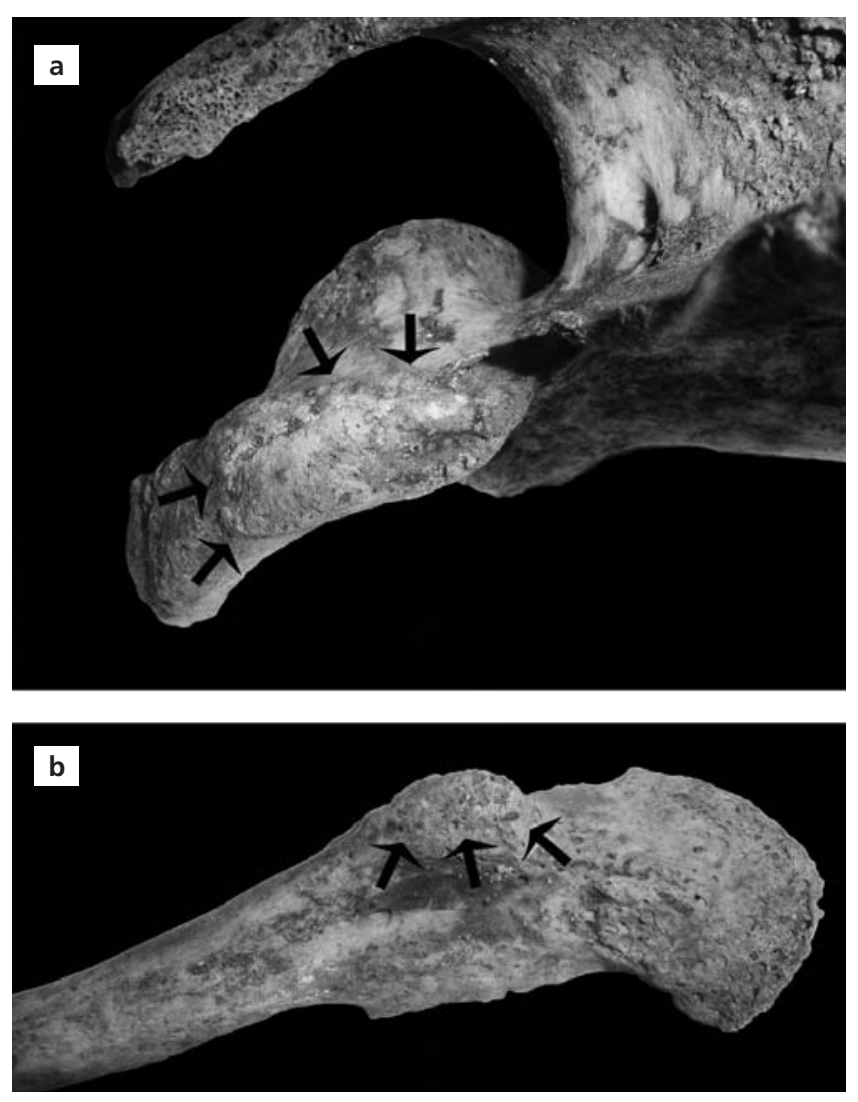

Figure 1. Articular facets (arrows) (a) on the superomedial aspect of the coracoid process, and (b) the conoid tubercle of the clavicle. [Color figure can be viewed in the online issue, which is available at www. anatomy.org.tr] 
the frequency of this anatomical variation is $1-1.2 \%$. However, Cockshott ${ }^{[t]}$ reported that the coracoclavicular joint originated in Central Asia many years ago, where the incidence was up to $40.7 \%$ demonstrating a gradual decrease as we move away from that region. In Greece, we found the coracoclavicular joint surfaces in $6.5 \%$, whereas in two osteological studies which were carried out in Southern Europe, the incidence of this accessory joint was reported as $0.3 \%$ and $2.8 \%$, respectively. ${ }^{[7,10]}$

Based on the geographic distribution of the coracoclavicular joint, Cockshott argued that there is an autosomal dominant pattern of inheritance. ${ }^{[4]}$ Actually, the development of the coracoclavicular joint has been a controversial issue in the literature. Kaur and $\mathrm{Jit}^{[1]}$ and Pillay ${ }^{[12]}$ supported that the joint may develop more by genetics than by environmental factors or congenital abnormalities. On the other hand, Lan ${ }^{[13]}$ proposed that it is an acquired characteristic, resulting from occupational stress. Kaur and Jit ${ }^{[1]]}$ suggested that the coracoclavicular joint appears after the first decade. Nalla and Asvat ${ }^{[6]}$ reported that this joint results from larger scapulae and longer claviculae coupling with a normal-sized thoracic inlet, which may restrict associated movements of the scapula. The findings of Cho and Kang ${ }^{[5]}$ study are in accordance with the present study where the coracoclavicular joint surfaces were significantly more common in the oldest age group. The existence of the coracoclavicular joint facets has been more frequently in males than females, but no study reported any significant difference. ${ }^{[2,14]}$ In the present study, the accessory joint surfaces were more frequently found in males than females (8:6), without any statistical significance as well.

Nalla and Asvat found the coracoclavicular articular facets bilaterally in $47.9 \%$ and unilaterally in $30.4 \%$ of specimens. ${ }^{[6]}$ The relative percentages of Olotu et al.

Table 1

Incidence of coracoclavicular joint facets, and distribution by gender, side and age.

\begin{tabular}{llccc}
\hline & & $\mathbf{n}$ & $\begin{array}{c}\text { Coracoclavicular } \\
\text { joint facets }\end{array}$ & $\mathbf{p}$ \\
\hline Gender & Male & 105 & $8(7.6 \%)$ & 0.509 \\
& Female & 11 & $6(5.4 \%)$ & \\
\hline \multirow{2}{*}{ Side } & Right & 110 & $7(6.4 \%)$ & 0.943 \\
& Left & 106 & $7(6.6 \%)$ & \\
\hline \multirow{2}{*}{ Age } & $46-60$ & 55 & - & \\
& $61-75$ & 82 & $3(3.7 \%)$ & 0.002 \\
& $76+$ & 79 & $11(13.9 \%)$ & \\
\hline \multirow{2}{*}{ Total } & & 216 & $14(6.5 \%)$ & \\
\hline
\end{tabular}

were $11 \%$ bilateral and $89 \%$ unilateral. ${ }^{[3]}$ In the osteological study of Nehme et al., the coracoclavicular joint was equally found bilaterally and unilaterally, while in the radiological study of the same authors, the joint was bilaterally present in $40 \%$ and unilaterally in $60 \%$ of specimens. ${ }^{[14]}$ We observed the coracoclavicular joint facets in ten individuals, four bilateral and six unilateral. According to the majority of the literature, the coracoclavicular joint is more often located in the right side ${ }^{[2,3,5,14]}$ while Nalla and Asvat found a higher incidence in the left side. ${ }^{[9]}$ In our study, both sides presented the same prevalence of coracoclavicular joint surfaces.

Although a large conoid process of the clavicle usually articulates with the coracoid process of the scapula, in our series one clavicle was found to have an elongated conoid process with a rough and slightly sharp tip, but without any joint surface. In this case, there was no articular facet on the coracoid process of the ipsilateral scapula. Furthermore, raised bony lips around the insertion of the conoid ligament were found in eight clavicles without any sign of neoarthrosis in the corresponding scapula. Raised bony lips were also found around the insertion of the coracoclavicular ligaments on the coracoid processes of four scapulae without any sign of a coracoclavicular joint on the clavicle. A bony crest or lip can also be caused by a thickened and strong ligament. Thus, we believe that the raised bony lips only on one side of those 12 bones were caused by calcifications of the coracoclavicular ligaments, and therefore they were not considered as a coracoclavicular joint.

The articular facet of the coracoclavicular joint has been recognized in plain radiographs. ${ }^{[14-16]}$ CT scans may also reveal this joint. ${ }^{[15,16]}$ Although the presence of the joint is usually asymptomatic, occasionally it may be related with various clinical manifestations of the region. In particular, it has been associated with a humeral head fracture ${ }^{[17]}$ shoulder pain ${ }^{[18]}$ cervicobrachial syndrome ${ }^{[19]}$ and thoracic outlet syndrome. ${ }^{[20]}$ Wertheimer ${ }^{[18]}$ and Hall ${ }^{[2]}$ supported that the presence of this accessory joint may alter the biomechanics of the shoulder since it probably decreases the shoulder mobility. ${ }^{[18,21]}$ Coracoclavicular joint arthritis may be accompanied by pain in the shoulder with reflection in the neck, arm and chest. ${ }^{[2]}$ Moreover, this joint might be responsible for degenerative changes on neighboring joints. ${ }^{[2]}$ The coracoclavicular joint may be recognized in an anteroposterior radiograph of the shoulder. CT scans may also reveal and confirm the presence of the joint. In cases with residual symptoms, surgical resection of the accessory joint might be necessary. ${ }^{[2,2,23,24]}$

The limitation of the present study is that, as any osteologic study, ${ }^{[5,14]}$ the presence of the coracoclavicular 
joint can only be assumed by findings of the joint surfaces on the clavicle and the coracoid process. The existence of a true synovial joint can only be confirmed in cadaveric studies.

\section{Conclusion}

The findings of the present study favor that the coracoclavicular joint could be the result of degenerative changes. From a clinical point of view, this accessory joint may be incidentally noticed in a plain radiograph in asymptomatic patients, but it has been also associated with various clinical manifestations of the shoulder region.

\section{References}

1. Standring S, editor. Gray's Anatomy: the anatomical basis of clinical practice. 39th ed. Philadelphia (PA); Elsevier Churchill Livingstone; 2005. p. 817-9.

2. Gumina S, Salvatore M, De Santis R, Orsina L, Postacchini F. Coracoclavicular joint: osteologic study of 1020 human clavicles. J Anat 2002;201:513-9.

3. Olotu Joy E, Oladipo GS, Eroje MA, Edibamode IE. Incidence of coracoclavicular joint in adult Nigerian population. Scientific Research and Essay 2008;3:165-7.

4. Cockshott WP. The geography of coracoclavicular joints. Skeletal Radiol 1992;21:225-7.

5. Cho BP, Kang HS. Articular facets of the coracoclavicular joint in Koreans. Acta Anat (Basel) 1998;163:56-62.

6. Nalla S, Asvat R. Incidence of the coracoclavicular joint in South African populations. J Anat 1995;186:645-9.

7. Vallois HV. Les anomalies de l'omoplate chez l'homme. Bulletins et Mémoires de la Société d'Anthropologie de Paris 1926;7:20-37.

8. Gruber W. Die Oberschulterhackenschleibentel (Bursae mucosae supracoradoideae). Memoire de l'Academie Imperiale des Sciences. Series 3, St. Petersburg VII; 1861. p. 1.

9. Mann RW, Hunt DR. Photographic regional atlas of bone disease: a guide to pathologic and normal variation in the human skeleton. 2nd edition. Springfield: Charles C. Thomas; 2005. p. 137-40.
10. Bainbridge D, Tarazaga SG. A study of the sex differences in the scapula. The Journal of the Royal Anthropological Institute of Great Britain and Ireland 1956;86:109-34.

11. Kaur H, Jit I. Brief communication: coracoclavicular joint in Northwest Indians. Am J Phys Anthropol 1991;85:457-60.

12. Pillay VK. The coraco-clavicular joint. Singapore Med J 1967;8: 207-13.

13. Lane AW. Some points in the physiology and pathology of the changes produced by pressure on the bony skeleton of the trunk and shoulder girdle. Guy's Hospital Reports 1886;38:321-434.

14. Nehme A, Tricoire JL, Giordano G, Rouge D, Chiron P, Puget J. Coracoclavicular joints. Reflections upon incidence, pathophysiology and etiology of the different forms. Surg Radiol Anat 2004;26: $33-8$.

15. Haramati N, Cook RA, Raphael B, McNamara TS, Staron RB, Feldman F. Coraco-clavicular joint: normal variant in humans - a radiographic demonstration in the human and non-human primate. Skeletal Radiol 1994;23:117-9.

16. Ma FY, Pullen C. A symptomatic coracoclavicular joint successfully treated by surgical excision. J Shoulder Elbow Surg 2006;15:e1-e4.

17. Frasseto F. Tre casi di articolazione coraco-clavicolare osservati radiograficamente sul vivente. Nota antropologica e clinica. Estratto da La Chirurgia degli organi in movimento. 1921;5:116-24.

18. Wertheimer LG. Coracoclavicular joint; surgical treatment of a painful syndrome caused by an anomalous joint. J Bone Joint Surg Am 1948;30A:570-8.

19. Del Valle D, Giordano A. Sindrome doloroso cervicobrachial originado por articulacion coracoclavicular. Operacion-curacion. Revista Argentina Norteamericana Ciencas Medicas 943;1:687-93.

20. Hama H, Matsusue Y, Ito H, Yamamuro T. Thoracic outlet syndrome associated with an anomalous coracoclavicular joint. A case report. J Bone Joint Surg Am 1993;75:1368-9.

21. Hall FJ. Coracoclavicular joint. Br Med J 1950;1:766-8.

22. Paraskevas G, Stavrakas ME, Stoltidou A. Coracoclavicular joint, an osteological study with clinical implications: a case report. Cases J 2009;2:8715

23. Moore RD, Renner RR. Coracoclavicular joint. Am J Roentgenol Radium Ther Nucl Med 1957;78:86-8.

24. Saunders SR. Non-metric skeletal variation. In: Reconstruction of life from the skeleton. Işcan MY, Kennedy KAR, editors. New York (NY): Alan R. Liss; 1989. p. 95-108.

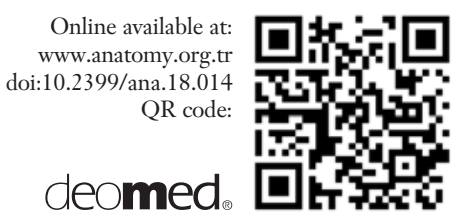

Correspondence to: Trifon Totlis, MD, PhD

Department of Anatomy and Surgical Anatomy, School of Medicine, Faculty of Health Sciences, Aristotle University of Thessaloniki, Thessaloniki, Greece Phone: +30 2310999072

e-mail: trifontotlis@gmail.com

Conflict of interest statement: No conflicts declared.

This is an open access article distributed under the terms of the Creative Commons Attribution-NonCommercial-NoDerivs 3.0 Unported (CC BY-NCND3.0) Licence (http://creativecommons.org/licenses/by-nc-nd/3.0/) which permits unrestricted noncommercial use, distribution, and reproduction in any medium, provided the original work is properly cited. Please cite this article as: Totlis T, Paparoidamis G, Trentzidis K, Otountzidis N, Piagkou M, Natsis K Coracoclavicular joint: clinical significance and correlation to gender, side and age. Anatomy 2018;12(2):57-60. 